\begin{tabular}{|c|c|c|}
\hline $\begin{array}{l}\text { PKS } \\
\text { PUBLIC } \\
\text { KNOWLDEE } \\
\text { PROJECT }\end{array}$ & $\begin{array}{c}\text { Revista de GEOGRAFIA } \\
\text { (RECIFE) } \\
\text { nttp://www.revista.uffe.br/revistageografia }\end{array}$ & $\begin{array}{l}\text { OJS } \\
\frac{\text { OPEN }}{\text { OPENAL }} \\
\text { SYSTEMS }\end{array}$ \\
\hline
\end{tabular}

\title{
A CONSERVAÇÃO DO PARQUE 13 DE MAIO EM RECIFE: UMA HISTÓRIA FRAGMENTADA
}

\author{
Luisa Acioli dos Santos ${ }^{1}$ \\ ${ }^{1}$ Mestranda em Desenvolvimento Urbano na Universidade Federal de Pernambuco. \\ Email: acioli.luisa@gmail.com
}

Artigo recebido em 28/08/2017 e aceito em 01/10/2017

\begin{abstract}
RESUMO
O Parque 13 de Maio, primeiro parque urbano histórico do Recife, recebeu intervenções pontuais que podem se constituir como ameaças à conservação do projeto original. Portanto, esta pesquisa tem como objetivo analisar as interferências realizadas no parque que implicaram em alterações no mobiliário e nas edificações no período de 2000 a 2011. A leitura relativa à conservação presente nas Cartas Patrimoniais e os conceitos de integridade e autenticidade foram essenciais para a vinculação do parque à categoria de jardins históricos e posterior avaliação das intervenções. Foi constatado que o Parque 13 de Maio, num contexto de dinamização, recebeu acréscimos conflitantes com relação à unidade básica de composição da obra, aspecto que somado à falta de conhecimento acerca de projetos paisagísticos aumenta a possibilidade de descaracterização do projeto. Mostrou-se essencial o investimento na educação patrimonial como forma de divulgação da relevância do parque para a cidade, contribuindo para uma conservação que envolva a participação da gestão pública, assim como dos usuários.
\end{abstract}

Palavras-chaves: Conservação. Jardim histórico. Parque.

\section{THE CONSERVATION OF PARQUE 13 DE MAIO IN RECIFE: A FRAGMENTED HISTORY}

\begin{abstract}
The Parque 13 de Maio, Recife's first historic urban park, has received occasional interventions that may constitute risks to the conservation of the original project. Therefore, this research has as objective to analyze the interferences made in the park that implied in alterations in the furniture and in the buildings from 2000 to 2011. The reading related to conservation in the Heritage Charters and the concepts of integrity and authenticity were essential for linking the park to the category of historical gardens and subsequent evaluation of the interventions. It was verified that the Parque 13 de Maio, in a dynamization context, received conflicting additions with respect to the basic unit of composition of the work, aspect that added to the lack of knowledge about landscape projects increases the possibility of project decharacterization. It was essential to invest in heritage education as a way of publicizing the park's relevance to the city, contributing to a conservation that involves the participation of public management, as well as of users.
\end{abstract}

Keywords: Conservation. Historic garden. Park. 


\section{INTRODUÇÃO}

No século XVII, na Inglaterra, os parques já existiam sob a forma de grandes campos utilizados pelos monarcas para a realização de práticas esportivas e atividades contemplativas. Estes parques da realeza ou parques de campo, traziam em seu traçado duas tendências distintas. Os parques ingleses refletiam princípios naturalistas e pictóricos, traziam traçados sinuosos e orgânicos, revelando a intenção de imitar a natureza em sua essência, criando relevos, rios, lagos, gramados e grupos de árvores sem aparente regularização de traçado. Em contrapartida, os parques franceses e italianos tinham traçados geométricos, baseados em conceitos de simetria e proporção. Eram parques carregados do desejo de dominar a natureza e reorganizar seus elementos visando traduzir o controle e a grandiosidade dos monarcas.

A partir do crescimento das cidades, estes parques de realeza foram sendo englobados pela administração municipal e administrados como parques públicos. Dentre os mais antigos de Londres, está o Hyde Park, que se tornou aberto para toda a população a partir de 1630 . Outro momento crucial no processo de surgimento dos parques foi impulsionado pela Revolução Industrial no século XIX. O Movimento dos Parques Públicos na Inglaterra motivou a visão dos parques urbanos como elementos de relevância para solucionar os problemas da população que sofria com a insalubridade, a difusão de epidemias e a alta taxa de mortalidade (SÁ CARNEIRO, 2010, p. 28).

O Parque 13 de Maio, foi um dos parques construídos tendo em vista o argumento embelezamento da cidade, promoção da saúde e elevação de espírito. Foi um dos espaços públicos mais desejados pelos recifenses, sobretudo intelectuais e empresários. Inaugurado no ano de 1939 com desenho de Domingos Ferreira, se configura como o primeiro parque urbano histórico da cidade. Localizado no centro do Recife, no bairro de Santo Amaro, o parque tem dimensão de 6,9 ha e se encontra na Zona de Preservação Histórica da Faculdade de Direito (ZEPH 17), desde 1980. Além de apresentar uma rica variedade vegetal, o parque conta com espaços para contemplação, áreas esportivas, edificações e monumentos de referência cultural.

No entanto, o parque recebeu diversas intervenções posteriores que somadas às falhas relativas ao gerenciamento e à conservação podem causar a descaracterização do mesmo. Esta ameaça sofrida pelo Parque 13 de Maio é um dos problemas que mais afeta os espaços públicos da cidade, visto que a desinformação acerca dos projetos paisagísticos atinge tanto os técnicos, arquitetos com uma formação que não contempla o paisagismo, quanto os 
responsáveis pela manutenção (Sá Carneiro, 2010, p. 16-18). Considerando que o número de espaços livres do Recife é insuficiente em relação à demanda da população, principalmente com relação aos parques com áreas recreativas maiores (Sá Carneiro e Mesquita, 2000, p. 38), torna-se extremamente necessário gerenciar estes espaços de forma a conservá-los.

O gerenciamento do projeto de parque urbano deve se estabelecer entre estes limites de mudança e permanência. De um lado, o projeto de parque é dinâmico e nunca está completo, pois adquire novos usos que se relacionam com as demandas da sociedade, seja por aspectos sociais, culturais, políticos e econômicos. Por outro lado, enquanto produto da história da população, o projeto do parque é testemunho dos valores de cada época e expressa a identidade do povo, portanto, deve ser entendido como patrimônio histórico e cultural. Por essa razão, se faz necessário compreender a categoria de jardins históricos segundo os postulados da Carta de Florença visando conservá-los num ato de respeito à natureza, à obra e ao legado humano.

\section{AUTENTICIDADE E INTEGRIDADE NOS JARDINS HISTÓRICOS}

O debate relativo à conservação e ao restauro de jardins históricos é recente se comparado às discussões relacionadas ao patrimônio arquitetônico. A carta de Veneza realizada em 1964 inseriu novos conceitos relacionados com a área envoltória dos bens tombados, compreendendo a visibilidade e a ambiência de entorno dos monumentos e dos próprios sítios urbanos como patrimônio, entendimentos significativos para as práticas de preservação da paisagem. Em 1981 foi elaborada a Carta de Florença, que se tornou um dos documentos de referência para ações de restauro de jardins históricos. $\mathrm{O}$ artigo $1^{\circ}$ da Carta de Florença coloca: "Um jardim histórico é uma composição arquitetônica e vegetal que apresenta interesse público dos pontos de vista histórico e artístico. Nesse sentido, deve ser entendido como "monumento",

A Carta de Florença considera o jardim como uma composição arquitetônica e vegetal que, portanto, é vivo, perecível e renovável, e se expressa pelo equilíbrio entre o movimento natural de definhamento da natureza e a vontade da arte de perenizar seu estado. A Carta destaca no artigo $4^{\circ}$ os elementos da composição do jardim histórico como: o plano e os diferentes perfis do terreno; as massas vegetais, suas essências, seus volumes, seu jogo de cor, seus espaçamentos, suas alturas respectivas; os elementos construídos ou decorativos; as águas moventes ou dormentes, reflexo do céu. E estabelece que a proteção dos jardins 
históricos exige a identificação, a realização do inventário e intervenções de manutenção, conservação, restauração e eventualmente, de reconstituição.

A Carta Brasileira de Jardins Históricos, conhecida como Carta de Juiz de Fora, elaborada em 2010, inclui como jardins históricos locais de importância simbólica e afetiva, de encontro e convívio, como parques, largos, praças, alamedas, hortos, pomares, cemitérios e jardins, por exemplo. A Carta aponta a relevância dos jardins históricos como o testemunho da relação entre cultura e natureza. Preservar estes jardins é salvaguardar a história das intervenções ali realizadas e o espírito do lugar. A autenticidade e a integridade são consideradas como fundamentais para a avaliação dos jardins históricos. O conceito de autêntico está relacionado a ser legítimo, genuíno, uma evidência verdadeira de algo. $\mathrm{Na}$ Carta dos Jardins Históricos Brasileiros (2010), a autenticidade é colocada como o grau de originalidade dos diferentes elementos de um mesmo sistema:

[...] A autenticidade de um jardim histórico, como em qualquer outro bem cultural, depende de quanto seus materiais são originais ou genuínos, levando-se em conta quando e como foi construído, considerando-se o envelhecimento e mudanças que o afetaram ao longo do tempo. A maioria dos bens históricos é alterada pela ação da natureza e pelo modo como são utilizados, sendo as mudanças consideradas como parte da estratificação histórica do bem. (Carta de Juiz de Fora, 2010, p. 4).

A Carta de Veneza de 1964 coloca que a autenticidade não se limita a consideração da forma e estruturas originais, mas inclui todas as modificações subsequentes e adições que possuem valor histórico e artístico. No livro Manual de Intervenções em Jardins Históricos, Carlos Fernando de Moura Delphim (2005) estabelece que a autenticidade deve considerar o período de elaboração do objeto, o período entre a fase de criação e o presente, e a atual percepção consciente que se tem do monumento. Novas intervenções, destruições e inserções de novos elementos num jardim histórico podem ameaçar sua autenticidade, todas as fases de estratificações históricas devem estar relacionadas em torno de uma mesma unidade.

A unidade tem relação com a compreensão da essência da obra, sendo assim, os elementos não podem ser vistos de forma autônoma, mas como partes de uma compreensão única. Nesse entendimento, o aspecto artístico de uma obra de arte depende da capacidade de transmitir a unidade através de suas partes. Esta essência será reconhecida no presente, na mente da pessoa que a observa e reconhece seu valor. Sendo assim, Jokilehto (2006, p. 4-5) estabelece que o conhecimento de sua verdade pode ocorrer em diferentes graus de escopo, 
constância e lucidez, e a preservação depende desse fator. Mesmo quando uma obra perdeu seu funcionamento original, ainda pode oferecer uma lembrança disso, o que contribui para estabelecer o seu significado no presente. A conservação de um monumento depende, portanto, da compreensão do material, mas também do imaterial, da apreciação do mundo dos significados.

De acordo com Stovel (2007), a proximidade dos conceitos ainda pode causar confusão visto que a autenticidade normalmente é entendida como a capacidade de um bem transmitir seu significado ao longo do tempo e a integridade, como a capacidade de um bem assegurar ou sustentar seu significado. Na Carta dos Jardins Históricos Brasileiros (2010) a integridade diz respeito ao grau de equilíbrio que os elementos que compõem o jardim mantêm entre si:

O conjunto de elementos que configuram um sítio histórico forma uma unidade básica. A partir dessa compressão, pode-se descrever cada elemento, cada parte, tendo por base a intenção original. A integridade se refere ao quanto o bem é completo e ao quanto preserva do equilíbrio entre os diversos elementos componentes. Suas qualidades intrínsecas estão relacionadas à qualidade dos materiais, a sua construção, desenho e localização. (Carta de Juiz de Fora, 2010, p. 4).

O parágrafo 88 das Diretrizes Operacionais da Unesco (2005) coloca que a integridade é uma medida da inteireza e de estar intacto do patrimônio natural e/ou cultural e seus atributos. Examinar as condições de integridade exige avaliar até que ponto a propriedade: a) inclui todos elementos necessários para expressar seu valor universal excepcional; b) tem tamanho adequado para garantir a representação completa dos recursos e processos para transmitir o significado do bem; c) sofre de efeitos adversos de desenvolvimento e/ou negligência.

Jokilehto (2006, p. 14) classifica três tipos de integridade: sócio funcional, estrutural e visual. A integridade sócio funcional de um bem é embasada na identificação das funções e processos associados à interação em sociedade, como respostas espirituais, utilização dos recursos naturais e movimentos dos povos. A integridade estrutural é definida pela identificação espacial dos elementos que documentam tais funções e processos, referindo-se ao que resistiu ao longo do tempo, sendo testemunho da criatividade de um povo e dando sentido à toda a área. A integridade visual, se relaciona com a definição da estética e de visadas no presente como resultado de certos processos. De acordo com Ribeiro e Lira (2012, 
p. 38) esses três aspectos se sobrepõem e quando analisados em conjunto, revelam a medida da integridade do bem.

Os conceitos de autenticidade e integridade são base para a classificação ou o tombamento dos bens e ao mesmo tempo são elementos-chave para a determinação de como será realizada a proteção e a manutenção destes bens. No entanto, são conceitos ainda em construção, que compõem uma série de problemáticas para a sua aplicação. Ribeiro e Lira (2012, p. 36) colocam que ainda existem lacunas na operacionalização, na descrição detalhada dos atributos e de como eles devem ser verificados. Estes conceitos enquanto teoria e dimensão prática ainda estão se consolidando e precisam ser aprofundados.

\section{PRIMEIRO PARQUE URBANO HISTÓRICO DO RECIFE}

O início das discussões acerca da criação do projeto do Parque 13 de Maio se deu no período da Revolução Industrial, em que os debates internacionais estavam voltados para a busca de soluções para os problemas das classes populares que viviam em moradias pequenas, úmidas e amontoadas. Segundo George Casé (2005, p. 215-221), no livro História e paisagem: ensaios urbanísticos de Recife e de São Luís, desde o primeiro momento de discussão sobre o Parque 13 de Maio, havia a intenção de criação de um elemento marcante de destaque na paisagem essencialmente edificada do bairro de Santo Amaro.

De acordo com Sá Carneiro (2010, p. 85), o primeiro a apresentar indicações quanto à criação do parque foi o engenheiro francês Louis Léger Vauthier que chegou ao Recife em 1840 e na direção da Repartição de Obras Públicas demonstrou o interesse de criar um passeio público que seria utilizado pela população de bairros centrais (FREITAS, 2006). O segundo projeto para o parque foi desenhado em 1860 pelo engenheiro inglês William Martineau. O projeto foi concebido a partir dos elementos existentes, tendo a linha de força do teatro Santa Isabel como ponto de partida, a vegetação foi utilizada com partido estético, orientando espaços de estar e de circulação pelo cruzamento de dois eixos numa grande praça central circular.

Além destes dois projetos mais três foram documentados por Freitas (2006): o "Projeto de Arruamento do Jardim 13 de Maio" de 1899, o "Projeto do Passeio Público 13 de Maio" em 1911 e o "Projeto do Parque 13 de Maio" de 1923. Um aspecto a ser ressaltado nestes três projetos é a existência do nome do espaço verde em questão, que foi escolhido de acordo com a data de início da construção do jardim que seria realizada no dia 13 de maio de 1889 em 
comemoração ao primeiro ano da abolição. No entanto, as obras foram iniciadas apenas no governo do General Barbosa Lima $(1892$ - 1896) e foram paralisadas com o fim do mandato.

Após um longo período de discussões, intelectuais, arquitetos, engenheiros, sociólogos e jornalistas impulsionaram a criação do parque se utilizando, sobretudo, do argumento ecológico (SÁ CARNEIRO, 2010, p. 92-94). As linhas idealizadas pelo engenheiro Domingos Ferreira para o Parque 13 de Maio valorizaram a paisagem recifense através do enaltecimento aos três elementos naturais: ar, sol e vegetação. Assim, no dia 30 de agosto de 1939, o parque foi inaugurado tendo em vista a realização de dois eventos importantes para a cidade: o III Congresso Eucarístico Nacional e a Grande Exposição Nacional de Pernambuco. O projeto se tornou um marco na modernização do Recife, sendo considerado um empreendimento de grande impacto urbanístico e efeito cívico para a cidade (FREITAS, 2006).

O sítio do parque apresentava o formato de "L" invertido, com área de 11.3 ha. No entorno, havia um conjunto de prédios voltados para a Rua da Saudade, a Escola Normal e a Faculdade de Direito. Este edifício foi tomado como ponto de partida para a definição do traçado do Parque 13 de Maio, mostrando a subordinação do traçado do parque à edificação monumental, característica do jardim francês (FREITAS, 2006). O parque era cortado por um eixo principal retilíneo que surgia da edificação da Faculdade de Direito, passava por um espaço elíptico e por último por uma área para esportes circular. O eixo principal era ladeado por fileiras de árvores simetricamente ordenadas e a área circular ficava rodeada por um gramado. O conjunto das edificações e das porções ajardinadas trazia a possibilidade de perspectivas grandiosas fortalecendo a função contemplativa que era predominante no parque.

Os dois eixos secundários e o eixo principal demarcavam a influência do traçado francês e o espírito de ordenação da natureza pelo homem. Já os caminhos secundários e curvilíneos mostram os princípios do jardim inglês, rompendo com a rigidez e possibilitando novas trajetórias pelo parque. Outro aspecto característico do jardim inglês utilizado por Domingos Ferreira foi a distribuição da vegetação, por vezes ao longo de alamedas e outras vezes utilizadas em grandes grupos arbustivos ou gramados distribuídos informalmente. $\mathrm{O}$ elemento água foi utilizado nas intersecções entre os eixos principal e secundário, duas fontes luminosas circulares foram inseridas simetricamente na praça elíptica. Eram novidades para a época, foram importadas e traziam a ideia de inovação e beleza ao parque. O traçado do parque se destaca como elemento de maior força no projeto realizando uma continuidade de composição entre as linhas do parque com o jardim da Faculdade de Direito. 


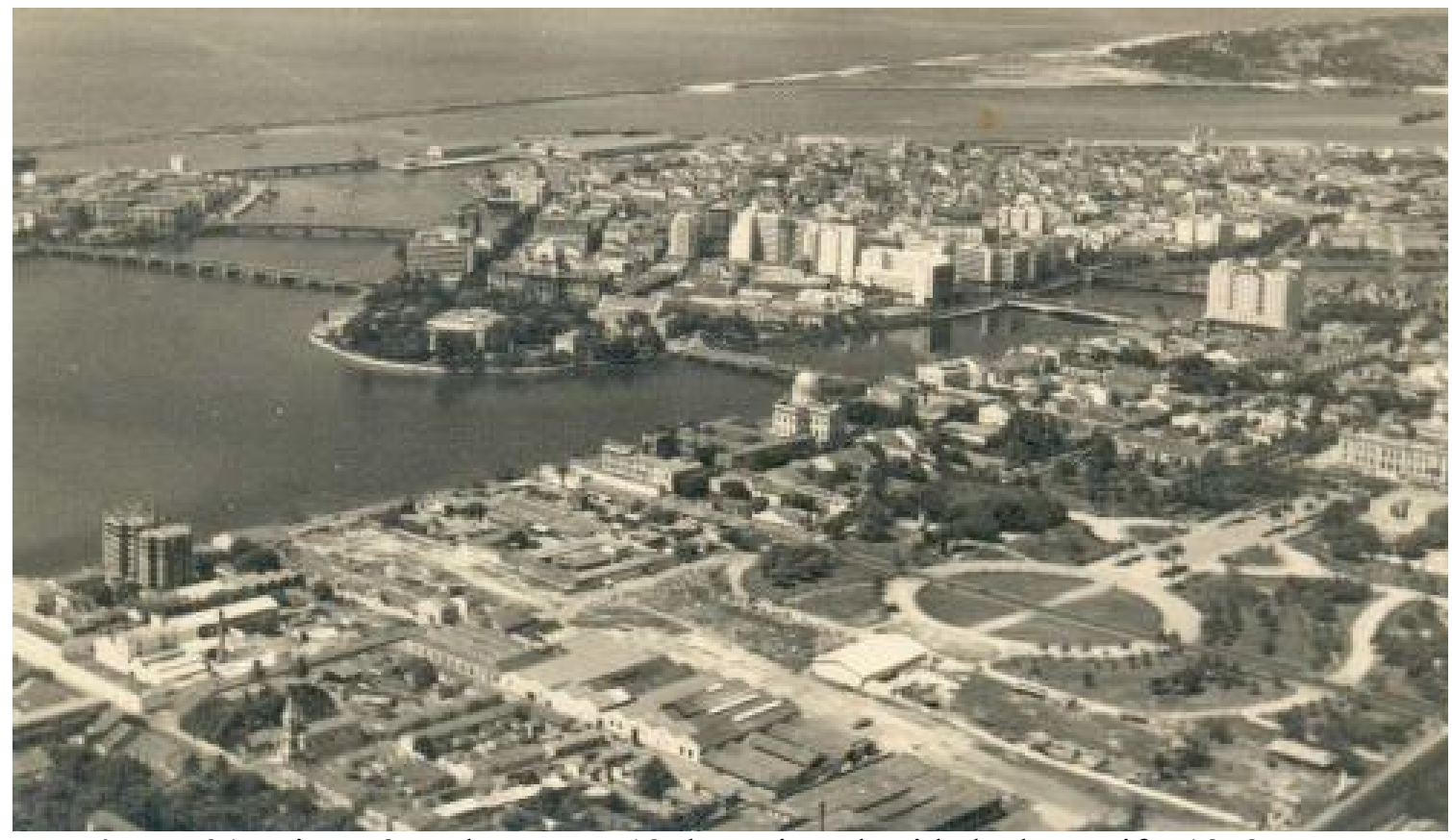

Figura 01: Vista aérea do Parque 13 de Maio e da cidade do Recife, 1952. Fonte:

http://www.fotolog.com.br/tc2/47546279/

Ao longo dos anos o parque sofreu algumas modificações, dentre elas a mais significativa foi a construção em 1958 do conjunto de edifícios do Instituto de Educação de Pernambuco (IEP) numa área pertencente ao Parque 13 de Maio. Cortando a área circular ao meio, provocando a fragmentação do traçado e a criação da Rua João Lira em um dos eixos secundários retilíneos. O monumento para homenagear a Força Expedicionária Brasileira (FEB) foi instalado num talude em 1971 para minimizar o impacto estético. Em 1970, houve uma grande melhoria do aspecto paisagístico com a introdução de escorregos e esculturas de Abelardo da Hora, que contribuíram tanto para o aspecto contemplativo quanto para o aspecto recreativo. A preocupação ecológica influenciou na criação do mini zoológico na mesma época.

Na década de 1980, o Parque 13 de Maio passou a fazer parte da Zona de Preservação Histórica da Faculdade de Direito conhecida como ZEPH 17. De acordo com Freitas (2006) em 1985, novos canteiros foram inseridos no eixo principal, modificando as perspectivas, obstruindo a visada que relacionava a Faculdade de Direito ao monumento da FEB, enfraquecendo a imponência do eixo principal. Novos caminhos secundários foram criados de acordo com os caminhos espontâneos da população, devido a utilização de pedras retangulares para o revestimento, os novos passeios tinham formas geométricas irregulares. No livro Parque e Paisagem: um olhar sobre o Recife Sá Carneiro (2010, p. 98) afirma: “[...] o projeto de um parque não é definitivo. Pode acompanhar as mais variadas formas de 
mudança social, e este é um fator determinante a ser considerado por planejadores e paisagistas em suas decisões".
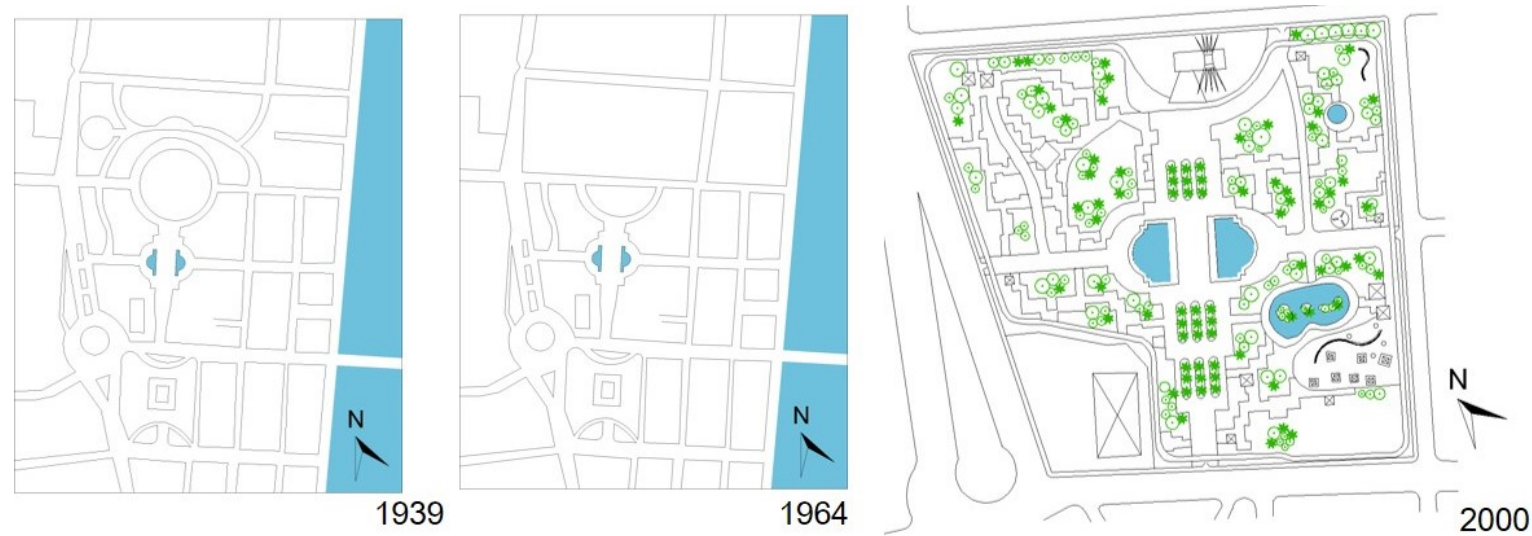

Figura 02: Plantas do Parque 13 de Maio digitalizadas por Luisa Acioli. Fonte: Sá Carneiro, 2010 .

\section{POR UMA CONSERVAÇÃO DO PARQUE 13 DE MAIO}

A paisagem do Parque 13 de Maio configurada ao longo dos anos guarda parte da história do Recife, pelos elementos construídos, monumentos e esculturas, pela vegetação, pelos edifícios do entorno, por sua localização e pela época de criação. Mesmo estando integrado o Setor de Preservação Rigorosa (SPR) da ZEPH 17, o parque apresenta uma proteção legal pouco esclarecedora na definição de práticas para orientar as intervenções. De acordo com a arquiteta da Empresa de manutenção e limpeza urbana (EMLURB), Maria Inês de Oliveira, a partir dos anos 2000 ocorreram a maior parte das intervenções que podem ameaçar a autenticidade e integridade, comprometendo a unidade do projeto do parque. Sendo assim, esta análise tem como foco vislumbrar as possíveis descaracterizações ocorridas através de intervenções pontuais.

Os critérios a serem considerados tem como base aqueles indicados pela Unesco em 2005 para a avaliação da autenticidade e os de referência para a integridade por Jokilehto (2006), ambos citados neste texto. Além destes, as contribuições de Sá Carneiro (2010, p. 111) para a análise de parques também foram de extrema relevância para a definição dos critérios. Sendo assim, a análise considera os seguintes princípios: funções, considerando o equilíbrio entre as áreas recreativas e contemplativas; usos, conforto dos usuários e segurança; integração visual pela transparência da paisagem; relação estética com elementos do entorno, em termos de forma, proporção, textura e cor. 
As alterações ocorridas no ano de 2001 foram realizadas pela prefeitura do Recife através do "Projeto de Acessibilidade do Parque 13 de Maio", em que o eixo principal e os eixos secundários receberam um novo revestimento no lugar das pedras com junta de grama. Também foi inserida uma rampa de acesso ao monumento à FEB e segundo a arquiteta da prefeitura, Maria Inês de Oliveira, ocorreu a ampliação das jaulas do mini zoológico e foi criada uma nova área recreativa com brinquedos para crianças. A inserção do espaço para jogos foi realizada para ampliar os tipos de atividades no parque e tem destaque por sua localização voltada para o acesso principal do parque, de frente para o edifício da Faculdade de Direito e ao lado do edifício da antiga Escola Normal. A Academia da Cidade foi inaugurada no mês de agosto de 2011 e fez parte do projeto da Prefeitura do Recife. No Parque 13 de Maio a estrutura é dotada de: edifício de suporte; rampas de acesso para pessoas com necessidades especiais; pranchas para abdominais; pisos táteis; barras de alongamento e mesas com cadeiras.
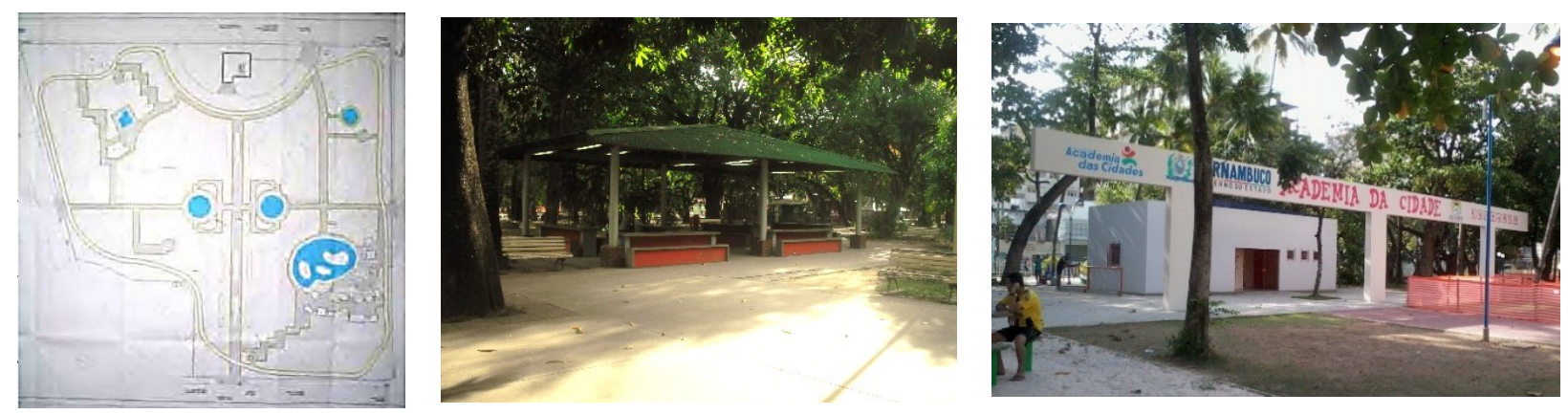

Figura 03: "Projeto de Acessibilidade do Parque 13 de Maio" 2001. Fonte: Freitas, Cândida (A) Foto do Espaços para Jogos. Fonte: Luisa Acioli, 2013 (B) Foto da Academia da Cidade do Parque 13 de Maio. Fonte: Luisa Acioli, 2013 (C)

\section{Funções e equilibrio entre as áreas recreativas e contemplativas}

No que tange as questões relativas à função, as mudanças de 2001 tentaram estabelecer um equilíbrio entre as áreas recreativas e as áreas contemplativas. A inativação do tanque de jacarés com a retirada dos animais provocou a diminuição das áreas contemplativas e o aumento das áreas recreativas, com a criação de uma nova zona de brinquedos na área livre próxima ao tanque. Para compensar a perda da área contemplativa, o número de jaulas do mini zoológico foi ampliado. O zoneamento de atividades estabelecido pelo traçado foi modificado em 2001, consolidou-se um novo zoneamento composto por uma linha divisória separa a porção sul do parque como a área mais contemplativa e a porção norte como a área mais recreativa.

Já em 2011, o incentivo à prática de esportes e ginástica foi amplamente estimulado como forma de combater o estresse cotidiano da vida urbana, por esta razão a tendência de 
difusão das academias por toda a cidade se configura como uma forma de adequar os espaços às novas demandas da sociedade. A função recreativa proporcionada pela Academia da Cidade atraiu os moradores mais próximos da área, que passaram a usufruir diariamente do espaço, renovando sua relação com o parque através de novas experiências.

\section{Usos, conforto dos usuários e segurança}

A criação da nova área recreativa em 2001 causou impacto no uso dos espaços, pois ocorreu uma migração dos usuários da área de lazer já consolidada, onde se encontram os escorregos de Abelardo da Hora, para a nova área recreativa. A localização dos novos brinquedos na porção oeste do parque assegurou a presença dos alunos das escolas do entorno. Estes adentram o parque através da Rua do Hospício e se instalam no ambiente recreativo no fim de tarde quando há sombra. Somada à intervenção da Academia da Cidade, o uso recreativo se fortaleceu no parque, mesmo assim ao realizar as entrevistas com os usuários em 2013 era perceptível que o uso contemplativo permanecia consolidado.

Já o espaço para jogos, embora tenha função ligada ao estímulo da interação social pela prática de jogos de tabuleiro (dominó, cartas, damas e xadrez), atrai a maioria dos usuários por outra razão. O espaço é um dos poucos no parque em que as pessoas podem ter fácil acesso para se abrigar das intempéries e seu uso está relacionado a atividades distintas: as pessoas costumam realizar as refeições, dormir e ler no ambiente.

No quesito referente ao conforto dos usuários todas as intervenções apresentam problemas no mobiliário. Os bancos circundantes a área do mini zoológico tem proporções que dificultam seu uso, altura do assento diminuta com dimensões que não se adequam bem as dimensões do corpo humano. O mobiliário do espaço para jogos é composto por bancos de concreto fixos em relação às mesas também de concreto e o espaço para acomodar as pernas entre eles é mínimo. O mesmo ocorre nas mesas e bancos instalados pela Academia da Cidade, são bancos de concreto sem encosto com dimensões do assento reduzidas, dificultando a permanência dos usuários.
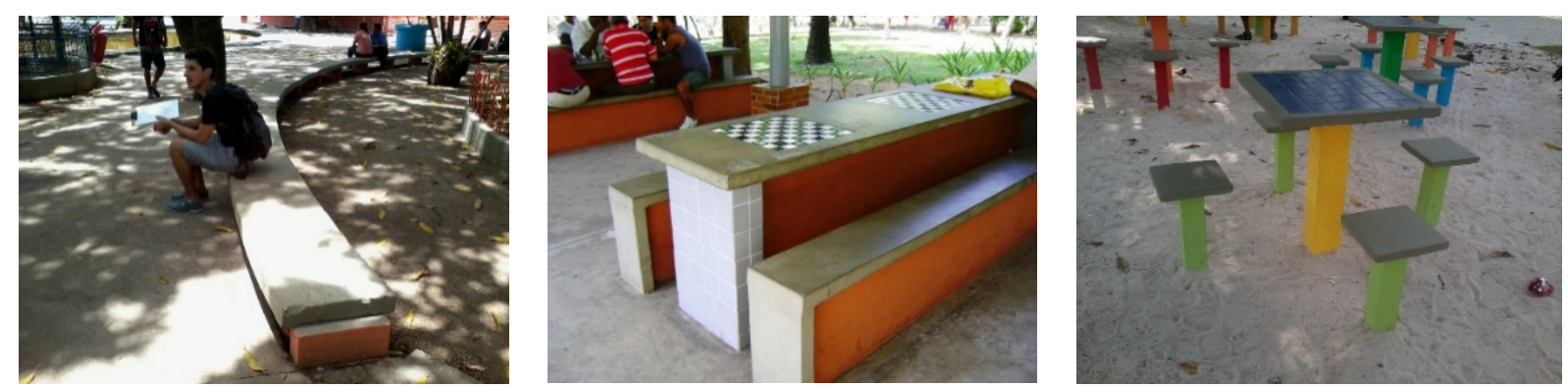

Figura 04: Fotos dos bancos do Parque 13 de Maio. Fonte: Luisa Acioli, 2013. 
Um dos maiores problemas do Parque 13 de Maio, comentados pelos funcionários e pelos usuários, é a falta de segurança. Há ocorrências de assaltos a qualquer hora do dia, como notificado em matérias do Jornal do Comércio (2016). Numa entrevista realizada em 2013 a área próxima ao monumento à $\mathrm{FEB}$ foi identificada como a mais perigosa pelos funcionários por ser menos frequentada. Normalmente, usuários e traficantes de drogas costumam ficar no local, mesmo com a presença de policiais. Para alguns usuários, a presença da polícia no parque é motivo de segurança, enquanto para outros, é vista como uma constante ameaça de perigo que gera uma tensão no ambiente do parque, impedindo o relaxamento e o lazer.

\section{Integração visual pela transparência da paisagem}

A transparência da paisagem foi violada pela construção de grandes paredes de alvenaria em algumas das jaulas do mini zoológico em 2001. Somada à disposição irregular das jaulas, criou barreiras visuais, obstruindo visadas interiores e exteriores que integravam, sobretudo, a área composta pelo lago e a Rua Princesa Izabel.
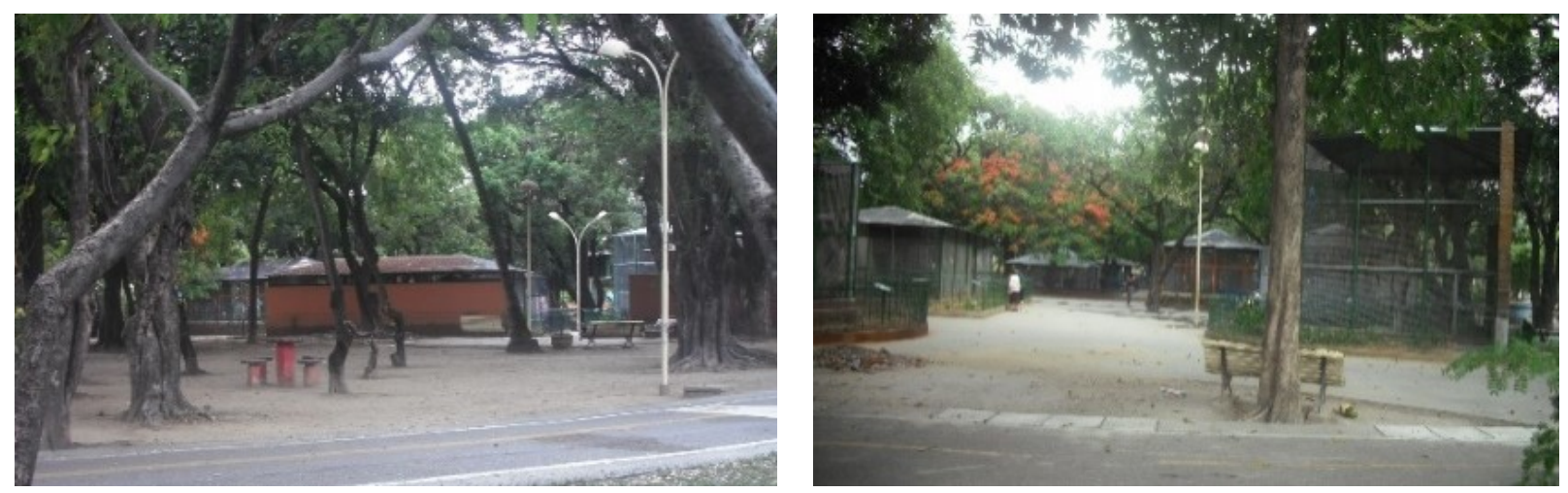

Figura 05: Foto das jaulas do mini zoológico. Fonte: Luisa Acioli, 2013.

Já a transparência alcançada na construção do espaço para jogos reflete sua condição de abrigo e local de proteção para os usuários. Constituída por seis pilares e por um telhado com quatro águas, a edificação do espaço para jogos permite a livre circulação do vento e a visualização do parque, agregando atividades contemplativas no espaço.

Com relação a Academia da Cidade, a transparência é praticamente nula, por ser configurada como uma caixa com poucas aberturas a edificação não se articula com a paisagem circundante. Seu volume chamou a atenção de uma usuária que atentou para o fato de que a edificação não considerara o clima da cidade, por não apresentar elementos que 
abrigam o homem da chuva ou do sol e destacou a ausência de beirais e de aberturas que provocassem a circulação do vento.

O edifício fica na esquina entre a Rua João Lira e a Rua da Saudade, provocando a obstrução da visualização de um dos ambientes mais belos do parque, que é a área onde estão presentes as figueiras e os escorregadores idealizados pelo artista Abelardo da Hora. A locação da Academia também trouxe problemas à segurança, visto que quem está caminhando nas ruas circundantes não pode visualizar o interior do parque, assim como as pessoas que estão dentro não tem uma visão abrangente do espaço que fica atrás da Academia, criando ambientes propícios para a ocorrência de crimes.

Relação estética com elementos do entorno, em termos de forma, proporção, textura e cor

No que se refere às relações estéticas com os elementos do entorno a inserção do mobiliário composto pelas jaulas e pelos brinquedos em 2001 demonstra o modelo de padronização das estruturas públicas. O valor artístico é desconsiderado nestes novos equipamentos, que são compostos de acordo com princípios econômicos e práticos. Há um contraste entre a beleza plástica dos escorregos idealizados por Abelardo da Hora, que fazem uma forte alusão ao tronco retorcido e entrelaçado das figueiras, e a pobreza formal representada por estes novos brinquedos.
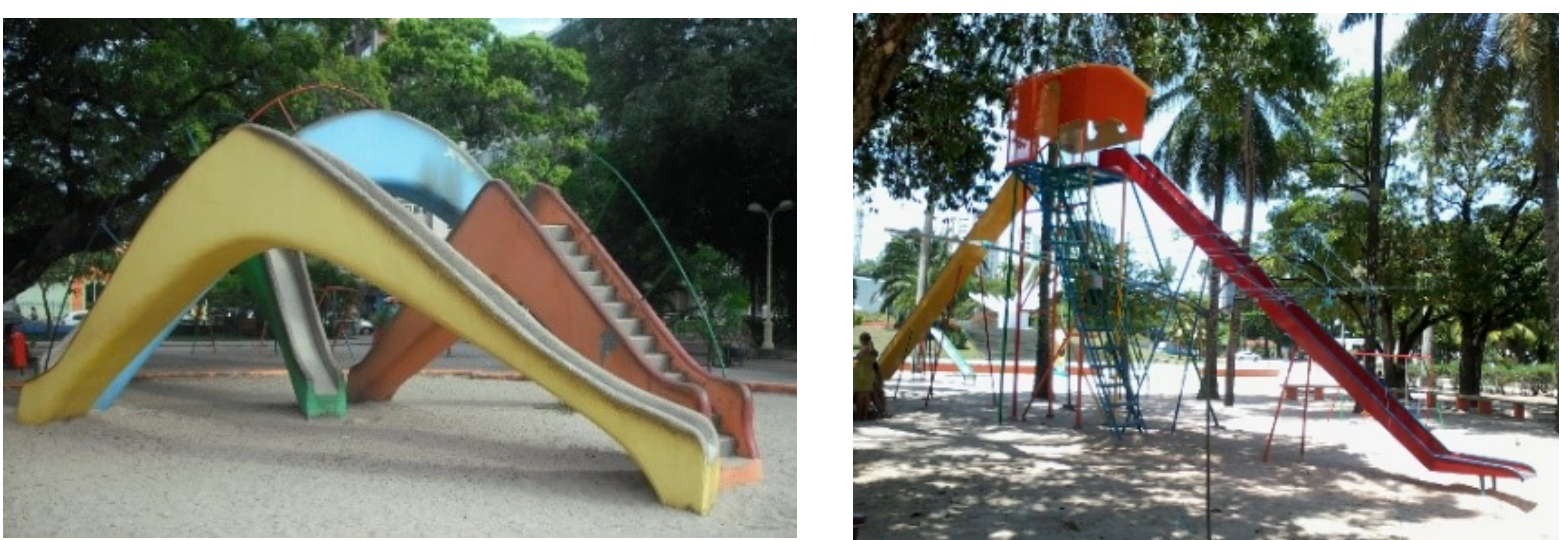

Figura 06: Contraste entre os escorregos de Abelardo da Hora e os escorregos na nova área recreativa criada em 2001. Fonte: Luisa Acioli, 2013

Em sua relação estética com os elementos do entorno, o espaço para jogos também desconsidera o caráter histórico e artístico das edificações do entorno. Assim como o edifício da Academia da Cidade, a paisagem circundante também não foi considerada de modo a estabelecer relações de volume, a forma, as cores e a escala da edificação vão de encontro à unidade básica de composição do projeto do parque. Esta unidade de composição está 
relacionada à grandiosidade que são afirmadas pela rigidez do traçado subordinado a uma edificação de referência arquitetônica, que é a Faculdade de Direito do Recife.

A Faculdade de Direto do Recife foi construída em estilo eclético com predominância do estilo neoclássico francês idealizado pelo arquiteto Gustave Varin e pelo engenheiro José Antônio de Almeida Pernambuco. A edificação de $3600 \mathrm{~m}^{2}$ se articula à Praça Adolfo Cirne adquirindo pela relação com a vegetação, maior monumentalidade. O edifício é registrado como Imóvel Especial de Preservação (IEP) e tombado pelo Instituto do Patrimônio Histórico e Artístico Nacional (IPHAN), no entanto, infelizmente para muitos recifenses a edificação passa despercebida, aspecto que pôde ser verificado durante as pesquisas de campo.
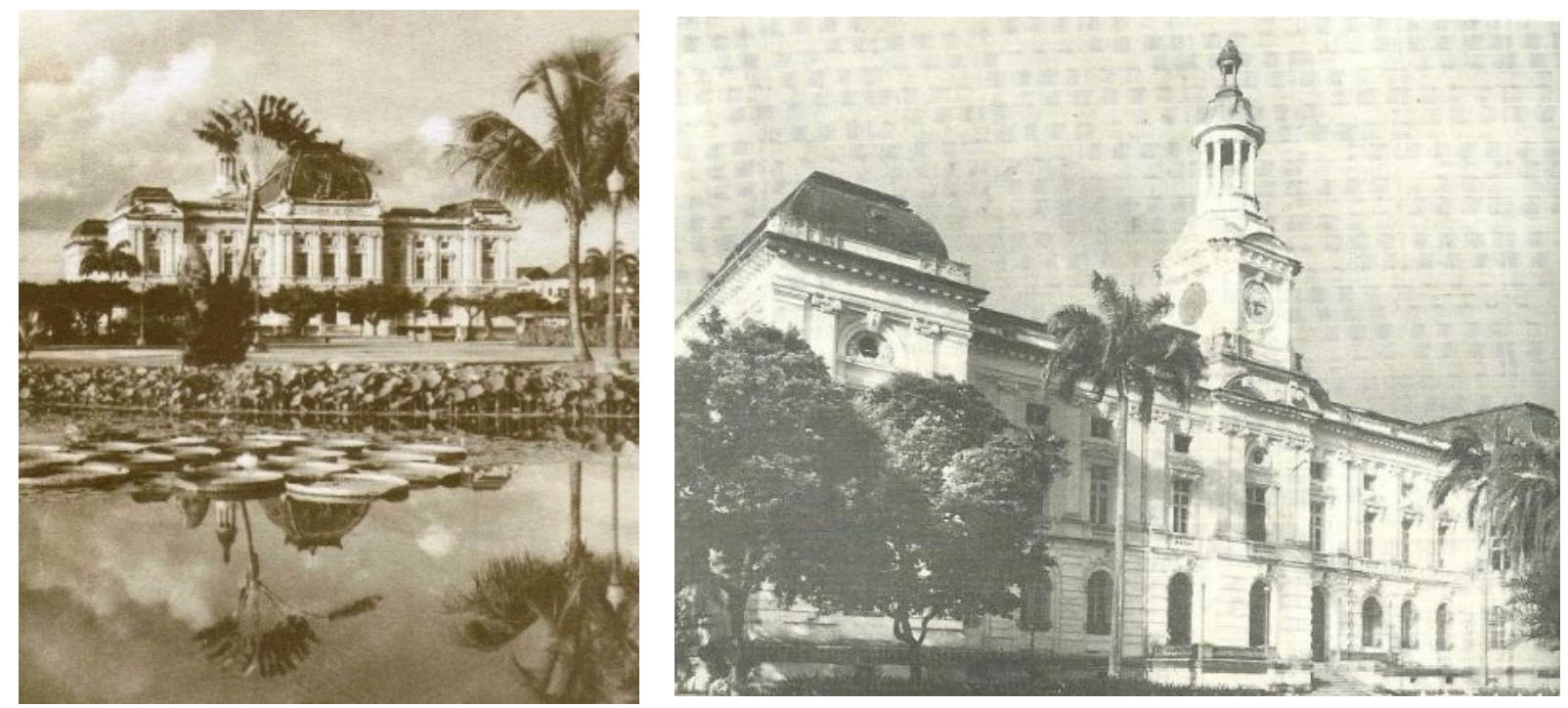

Figura 07: Vista da Faculdade de Direito a partir do lago, 193?. Acervo: Fundação Joaquim Nabuco (A). Edifício Faculdade de Direito. Fonte: Fabris (Org.), 2006 (B).

Nas intervenções mais recentes no parque os banheiros e a administração foram reformados, os equipamentos e as edificações foram pintados, assim como alguns canteiros de grama foram transformados em bancos de areia. As mudanças interferiram nas texturas e cores da paisagem do parque, a vivacidade dos novos tons utilizados em postes de iluminação, grades, bancos e brinquedos tiraram o foco que deveria ser dado à vegetação. A cor utilizada anteriormente no parque fazia referência ao revestimento presente no edifício da Faculdade de Direito evidenciando a integração entre os projetos. Atualmente, até mesmo a cor dos escorregos criados por Abelardo da Hora foi modificada, gerando questionamentos sobre a manutenção da autenticidade do elemento enquanto obra de arte, que provavelmente foi idealizado pelo artista como uma escultura em concreto sem revestimento de tinta. 


\section{CONSIDERAÇÕES FINAIS}

No Projeto do Parque 13 de Maio as linhas de composição da Faculdade de Direito foram tomadas como partido para a definição do traçado do parque que reforça a ortogonalidade e estabelece pontos focais demarcados por fontes e espelhos d'água numa linguagem rebuscada e variada. As alamedas de vegetação nos eixos ortogonais criam perspectivas que relacionam o interior do parque ao entorno, enquanto a vegetação que se distribui informalmente no restante do parque contribui para a criação de recantos, que valorizam a contemplação de elementos do próprio parque, como o lago ou o mini zoológico. Os elementos se integram numa linguagem estética notável, gerando uma ambiência majestosa que transmite orgulho aos usuários.

Infelizmente, as transformações provocadas pelos projetos inseridos a partir dos anos 2000 podem ser consideradas como ameaças ou riscos à conservação do parque, visto que desconsideram a unidade do projeto original, enfraquecendo sua autenticidade e integridade. Principalmente se levarmos em conta a linha de composição adotada no projeto do parque no que tange aos princípios de integridade visual, analisada através da transparência da paisagem. Negligenciada na elaboração do edifício da Academia da Cidade, por exemplo. Considerando a autenticidade, um dos critérios de destaque é a avaliação da forma e do design, aspectos considerados no item de relações estéticas, onde ficou claro a ausência de relações plásticas com as edificações do entorno, assim como com os monumentos artísticos de referência no parque, como as esculturas e os escorregos de Abelardo da Hora.

Com relação a integridade sócio funcional, examinada através da investigação da função e dos usos do parque, assistimos a uma transformação que tem levado o parque a abrigar cada vez mais equipamentos recreativos em lugar dos elementos contemplativos. Essa modificação é entendida como um reflexo das demandas da população e da própria carência de espaços de lazer no centro do Recife que possam abrigar essas funções. Desse modo, as alterações fazem parte da história do parque e podem ser realizadas desde que respeitem as relações formais e visuais que compõem a unidade do projeto original.

A localização e a configuração do parque proporcionaram sua representatividade enquanto plataforma de debate e reinvindicação pela população por sua condição de espaço público central de grande porte. Em contrapartida, a insegurança é apontada como um dos maiores problemas. A ocorrência de crimes está associada a falta de transparência em alguns pontos do parque, o que estimula a ocorrência de atividades ilícitas, como venda de drogas ou 
prostituição. Além disso, o desconforto proporcionado pelo desenho do mobiliário, em destaque, os bancos, dificulta a permanência dos usuários, interferindo no significado do parque enquanto lugar de repouso, paz e tranquilidade.

De um modo geral, o Parque 13 de Maio sofre de efeitos negativos de desenvolvimento e negligência não pela perda de elementos originais, mas pelo acréscimo excessivo de componentes que acabam por diminuir o efeito do conjunto. A autenticidade e a integridade da obra estão sendo enfraquecidas pela adição de edifícios e equipamentos que apresentam uma estética padronizada e generalizada que não acrescentam singularidade ao projeto do parque. Um parque enquanto lugar de encanto deve produzir sensações, passar sentimentos, e no caso do Parque 13 de Maio tudo converge para que uma sensação de beleza sublime, como se a paisagem do parque pudesse enobrecer o observador, transformando a experiência do espaço em algo esplêndido e excepcional. É necessário que as futuras intervenções possam enriquecer o discurso projetual do parque, fortalecendo a conservação da unidade de composição.

É necessária uma visão de gestão de espaços livres voltada para a educação patrimonial. A orientação dos profissionais e usuários através do conhecimento dos valores agregados ao parque é essencial para a efetiva conservação do projeto. Este cuidado com o patrimônio deve ser estimulado para favorecer o aprimoramento do olhar estético e ético da população com relação aos espaços livres da cidade, visto que alguns além de se configurarem como espaços de lazer apresentam o caráter de obras de arte. Para resgatar e conservar os valores desses projetos é necessário investir nesta missão de conscientização tão bem colocada pelo paisagista Burle Marx numa entrevista para o Diário de Pernambuco em 1937:

[...] a missão social do paisagista tem esse lado pedagógico de fazer comunicar às multidões o sentimento de apreço e compreensão de valores da natureza através do contato com o jardim e com o parque. (SILVA, 2007).

\section{REFERÊNCIAS}

CARTA DE JUIZ DE FORA. Instituto do Patrimônio Histórico e Artístico Nacional. IPHAN, Rio de Janeiro, Edições do Patrimônio, 2010.

CURY, I.. Cartas patrimoniais. IPHAN. Rio de Janeiro, Edições do Patrimônio, 2000.

DELPHIM, C. de M.. Manual de intervenções em jardins históricos. Rio de Janeiro, 2005. 
FABRIS, A. T.. (Org.). Ecletismo na arquitetura brasileira. Editora da Universidade de São Paulo. São Paulo, 2006.

FREITAS, C.. O Parque 13 de Maio na modernização do Recife. 2006. Dissertação em Desenvolvimento Urbano - Departamento de Arquitetura e Urbanismo, Universidade Federal de Pernambuco, Recife.

JOKILEHTO, J.. Considerations on Authenticity and Integrity in World Heritage context. In: City \& Times, 2:1, 2006.

JORNAL DO COMÉRCIO ONLINE. População reclama da falta de segurança no Parque 13 de Maio. Publicado em 14/05/2016. Disponível em: <http://jconline.ne10.uol.com.br/canal /cidades/geral/noticia/2016/05/14/populacao-reclama-da-falta-de-seguranca-no-parque-13-demaio-235706.php > Acesso em: 18 de julho de 2017.

PONTUAL, V.; SÁ CARNEIRO, A. R.. História e paisagem: Ensaios urbanísticos do Recife e de São Luís. Recife: Ed. Bagaço, 2005.

RIBEIRO, C; LIRA, F. Autenticidade, Integridade e Significância Cultural. In: N. Lacerda e S. M. Zancheti, (Org.). Plano de gestão da conservação urbana: conceitos e métodos. Editora: Centro de Estudos Avançados da Conservação Integrada. Olinda, 2012.

SÁ CARNEIRO, A. R.; MESQUITA L.. Espaços livres do Recife. Recife. Prefeitura do Recife, 2000.

SÁ CARNEIRO, A. R.. Parque e paisagem: um olhar sobre o Recife. Recife. Ed. Universitária da UFPE, 2010.

SILVA, A. F.. O projeto paisagístico dos jardins públicos do Recife de 1872 a 1937. 2007. Dissertação em Desenvolvimento Urbano - Departamento de Arquitetura e Urbanismo, Universidade Federal de Pernambuco, Recife..

STOVEL, H.. Effective use of authenticity and integrity as world heritage qualiifying conditions. City \& Time 2 (3): 3, 2007.

UNESCO. Operational guidelines for the implementation of the World Heritage Convention. 2005. 